\title{
First meteor radar observations of tidal oscillations over Jicamarca $\left(11.95^{\circ} \mathrm{S}, \mathbf{7 6 . 8 7}^{\circ} \mathrm{W}\right)$
}

\author{
L. Guo and G. Lehmacher \\ Department of Physics and Astronomy, Clemson University, SC, USA
}

Received: 30 September 2008 - Revised: 22 June 2009 - Accepted: 22 June 2009 - Published: 26 June 2009

\begin{abstract}
Tidal oscillations in the equatorial mesosphere and lower thermosphere (MLT) region over Jicamarca $\left(11.95^{\circ} \mathrm{S}, 76.87^{\circ} \mathrm{W}\right)$ are studied using the observations from the newly installed Jicamarca All-sky Specular MEteor Radar (JASMET). The vertical structure and seasonal variability of diurnal and semidiurnal tides from $80-100 \mathrm{~km}$ are presented.

The analyses show a strong diurnal tide over Jicamarca for both zonal and meridional components with the meridional amplitudes being larger than the zonal ones. Maximal diurnal amplitudes, $45 \mathrm{~m} / \mathrm{s}$ for zonal and $55 \mathrm{~m} / \mathrm{s}$ for meridional, are observed around equinox. The zonal diurnal amplitudes reach maxima at 90-96 km, while the meridional diurnal amplitudes grow with altitude for most months. Semidiurnal amplitudes vary not as strong as diurnal amplitudes.

The vertical structures of the tidal components are compared with Global Scale Wave Model (GSWM02) prediction and the tidal wind analysis results from TIDI measurements onboard of the TIMED satellite. The data from JASMET and TIDI show similar amplitudes for both diurnal and semidiurnal tides. GSWM02 overestimates diurnal amplitudes, but underestimates semidiurnal amplitudes for both zonal and meridional components.
\end{abstract}

Keywords. Meteorology and atmospheric dynamics (Middle atmosphere dynamics; Thermospheric dynamics; Waves and tides)

\section{Introduction}

Solar atmospheric tides, persistent global-scale waves with periods of integer fractions of a solar day, are one of the dominant oscillations in the MLT region. This kind of oscillation plays an important role in the dynamics of MLT be-

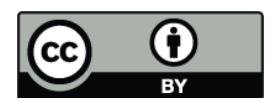

Correspondence to: L. Guo

(lguo@clemson.edu) cause it is one of the mechanisms for transferring energy and momentum from the lower to the upper atmosphere (Groves and Forbes, 1985). Solar tides are excited primarily by solar heating of water vapor in the troposphere and ozone in the stratosphere. The migrating or sun synchronous tides are driven by these sources, while the nonmigrating or non-sun synchronous tides are mainly driven by latent heat release (Hagan and Forbes, 2002, 2003) in the troposphere and nonlinear interactions between planetary waves and migrating tides (Forbes et al., 2003).

Extensive tidal observations in the MLT region have been conducted at high and middle latitudes with MF and meteor radars. The high latitude radar observations have shown that the semidiurnal tide is significantly larger than the diurnal tide (Avery et al., 1989) and migrating tides play a more important role than the nonmigrating tides in this region (Portnyagin et al., 2004). Comparable mid-latitude tidal observations show that the semidiurnal tide is generally larger than the diurnal tide (Manson et al., 1989). At Southern Hemisphere mid-latitudes, larger diurnal tides have been measured than in the Northern Hemisphere (Vincent et al., 1989). Global scale seasonal and interannual variations of the MLT tide have been established (e.g. Manson et al., 2002; Pancheva et al., 2002) consisting mostly of high and middle latitude radar data but sparse low-latitude observations. Vincent et al. (1998) compared MF radar measurements over Adelaide, Christmas Island, and Kauai and found strong seasonal and interannual change of diurnal tide amplitudes over the three sites. They also suggest a relationship between diurnal tidal amplitudes and stratospheric quasi-biennial oscillation. When the QBO is in the westward phase, the diurnal amplitudes are larger than the climatological average. When the QBO is eastward, the amplitudes are smaller than the average. But MF radars tend to underestimate winds above $90 \mathrm{~km}$ (Cervera and Reid, 1995), limiting their application on MLT tidal studies. With the introduction of satellite observations (HRDI, WINDII and TIDI) of the MLT winds, global tidal information (Burrage et al., 1995; McLandress et al.,

Published by Copernicus Publications on behalf of the European Geosciences Union. 
Table 1. JASMET configuration.

\begin{tabular}{ll}
\hline Parameter & Specification \\
\hline Frequency & $50 \mathrm{MHz}$ \\
Variable Peak power & $10,20,100 \mathrm{~kW}$ \\
Variable duty cycle & $1 \%, 2 \%, 5 \%$ \\
IPP & $\sim 5 \mathrm{~ms}$ \\
Four TX antennas & five-element Yagi \\
TX antenna elevation & $45^{\circ}$ \\
Five RX antennas & two-element Yagi \\
RX antenna azimuth & $45^{\circ}$ \\
Pulse Code & $4-$ bit: 1110 and 1101 complementary code \\
Pulse width & $10 \mu \mathrm{s}$ \\
\hline
\end{tabular}

1996; Wu et al., 2008) can be obtained from adequate local time coverage through sufficiently long composite data, e.g., 36 days for HRDI and WINDII, 60 days for TIDI. Thus satellite measurements provide only a smoothed picture of tides.

There have been limited tidal studies with meteor radars in the low-latitude MLT region. Most of them showed that migrating tides are the most prominent components and the diurnal tide is stronger than the semidiurnal tide. One of the earliest equatorial meteor radar experiments (Badadzhanov et al., 1973) detected the diurnal and semidiurnal tide in the lower thermosphere at Mogadishu, Somalia $\left(2^{\circ} \mathrm{N}\right)$ in 1968. Later with a meteor radar at Jamaica $\left(18^{\circ} \mathrm{N}\right)$, Scholefield and Alleyne (1975) showed the dominance of diurnal tide over other tidal harmonic components (12 or $8 \mathrm{~h}$ period). Meteor radar observations at Punta Borinquen, Puerto Rico $\left(18^{\circ} \mathrm{N}\right)$, showed that the diurnal wind amplitude increased from 15 to $34 \mathrm{~m} / \mathrm{s}$ but decreased significantly above $90 \mathrm{~km}$ (Bernard et al., 1981). Chang and Avery (1997) found considerable interannual and seasonal variation in the diurnal amplitudes over Christmas Island $\left(1.95^{\circ} \mathrm{N}\right)$. The recently installed meteor radar in Trivandrum, India $\left(8.5^{\circ} \mathrm{N}\right)$ found much stronger meridional tidal components than zonal ones (Deepa et al., 2006).

Even with decades of MLT tidal studies, the large tidal variability and the limited available observations in low latitude make the establishment of a complete tidal climatology difficult to achieve. In Jicamarca, Peru $\left(11.95^{\circ} \mathrm{S}, 76.87^{\circ} \mathrm{W}\right)$, Countryman and Dolas (1982) attempted tidal analysis from 3-day measurements in April, July, October and December with the powerful Jicamarca mesosphere-stratospheretroposphere (MST) radar. Due to the limitation of the MST radar, signals are not strong enough to be detected at night and the equatorial electro jet (EEJ) also prevents it from measuring wind over $90 \mathrm{~km}$. Countryman and Dolas (1982) analysed wind from $62-86 \mathrm{~km}$ and showed that diurnal phases occur later than model values and never observed large amplitude growth at $80 \mathrm{~km}$ as theories predicted. The newly installed JASMET at Jicamarca Radio Observatory (JRO) can operate longer hours and measure neutral wind continuously from $70-110 \mathrm{~km}$ giving us opportunity to extract complete MLT tidal components for the first time over Jicamarca. In the present study, the month-to-month variation of vertical characteristics of atmospheric tides in the equatorial MLT region using JASMET is presented. These are the initial results from the system, which are compared with TIDI satellite results (Oberheide and Forbes, 2008; Wu et al., 2008) and monthly GSWM02 (Hagan and Forbes, 2002, 2003) values which take into account both migrating and nonmigrating components. It serves to assess the present understanding of the tidal characteristics in low latitude MLT region.

In Sect. 2, the system details and the data analysis are described. The results are discussed in Sect. 3 and a summary is given in Sect. 4.

\section{JASMET experiment and data analysis}

JASMET is an all-sky interferometric specular meteor radar operated in a similar way as the meteor radar in Adelaide, Australia (Holdsworth et al., 2004). The hardware specifications and data processing software were provided by Atmospheric Radar Systems (Atrad) Pty. Ltd., while the hardware was produced and installed by Jicamarca.

JASMET was first operated in November 2005 as a proof trial with offline data processing. The first campaign of the integrated system including the on-line data analysis was conducted in June 2006. Since July 2007 JASMET has been operated regularly so that tidal analysis and studies are possible in the MLT region at Jicamarca.

Table 1 shows the basic specifications of the JASMET radar. JASMET operates at $50 \mathrm{MHz}$, with a variable peak power $(10 \mathrm{~kW}, 20 \mathrm{~kW}, 100 \mathrm{~kW})$ and variable duty cycle $(1 \%$, $2 \%$ and $5 \%$ ), depending on the application. The data in this paper had all been obtained with a peak power $10 \mathrm{~kW}$ and a duty cycle $5 \%$. On transmission a 4-bit complementary code is used so that the sidelobes are minimized to avoid multiple detection; range dealiasing is not necessary because the decoded range-aliased echo will generally not appear in the correct range (Holdsworth et al., 2004). The transmission system consists of four 5-element Yagi antennas, each of them pointing to the four cardinal directions with elevation angles of $45^{\circ}$. There is no vertical beam so that very little EEJ echoes are received. Reception is performed using five two-element Yagi antennas aligned along an azimuth of $45^{\circ}$, which are fed to a multi-channel multiple-purpose radar data acquisition system (RDAS) based on digital receiver technology. The receiving antennas use the configuration described by Jones et al. (1998), being arranged in two perpendicular arms with spacings of 2 and $2.5 \lambda(12 \mathrm{~m}$ and $15 \mathrm{~m}$ ). This configuration allows unambiguous angle-ofarrival estimation while minimizing antenna mutual coupling effects.

The data processing software generates zonal and meridional wind from radial velocities estimated (error 
Table 2. JASMET observations and comparison with TIDI.

\begin{tabular}{ccccc}
\hline Month & Year & Day number & Monthly TIDI data day number & Daily TIDI data day number \\
\hline Jan & 2008 & $26-28$ & & \\
Feb & 2008 & $32-37 ; 43-44 ; 47-58$ & & \\
Mar & 2008 & $81-84$ & & \\
Apr & 2008 & $95-98$ & 135 & $129-134$ \\
May & 2007 & $129-134$ & 166 & \\
Jun & 2006 & $167-170$ & 196 & \\
Jul & 2007 & $199-212$ & 227 & \\
Aug & 2007 & $213-218$ & 258 & \\
Sep & 2006 & $251-257$ & 288 & $319-325$ \\
Oct & 2007 & $293-296$ & 319 & $340-345$ \\
Nov & 2007 & $319-325$ & 349 & \\
Dec & 2007 & $340-345$ & & \\
\hline
\end{tabular}

$\sim 1-3.5 \mathrm{~m} / \mathrm{s}$ ) from meteor echoes in bins of $2 \mathrm{~km}$ and $1 \mathrm{~h}$ from $70-110 \mathrm{~km}$. The wind data used in our tidal analysis are from twelve-month observations in 2006-2008 (Table 2). The data were accumulated over monthly periods (3-20 days) to form effective 24-h data sets at each height of observation, and the hourly averaged zonal and meridional winds $(A(t)=u(t)$ or $v(t))$ were subjected to Fourier analysis. For all the data groups, 24-h (diurnal tide) and 12-h (semidiurnal tide) periods are the strongest, while 8 -h periods (terdiunal tide) are insignificant. For most days, diurnal tides dominate. On very few occasions, 12-h periods dominate. Thus we use a basic harmonic fit to generate prevailing component $a_{0}$ and only the diurnal $\left(a_{24}\right.$ and $\left.\phi_{24}\right)$ and semidiurnal $\left(a_{12}\right.$ and $\left.\phi_{12}\right)$ tidal components (Eq. 1).

$$
A(t)=a_{0}+a_{24} \cos \left(\frac{2 \pi t}{24 h}-\phi_{24}\right)+a_{12} \cos \left(\frac{2 \pi t}{12 h}-\phi_{12}\right)
$$

The time used in all the data analysis is in universal time (UT). When there were short gaps in the data, they were simply ignored from the least squares fitting routine without seriously affecting the results. A fit is only performed if at least 18 different hours are represented in the $24 \mathrm{~h}$ data set for a given height. In most months, from 80 to $100 \mathrm{~km}$, there were no longer than 6-h gaps in the data, which gave us continuous vertical profiles in this region. Values of amplitudes and phases from the fits were retained when the standard error (standard deviation/sqrt(sample size)) of the phases were less than $2 \mathrm{~h}$ for diurnal components and $1 \mathrm{~h}$ for semidiurnal components. In January 2008, only few data were retained due to large errors. Nevertheless, we show January results for completeness (Figs. 2-6). A typical comparison of measurements and a harmonic fit at a certain altitude is given in Fig. 1 . The vertical bars show the variation of hourly winds.

Next we briefly describe tidal analysis using TIDI winds. TIDI is a limb-scan Fabry-Perot interferometer installed on the TIMED satellite and measures wind daytime (70$120 \mathrm{~km})$ and nighttime $(80-103 \mathrm{~km})$ by scanning various air-

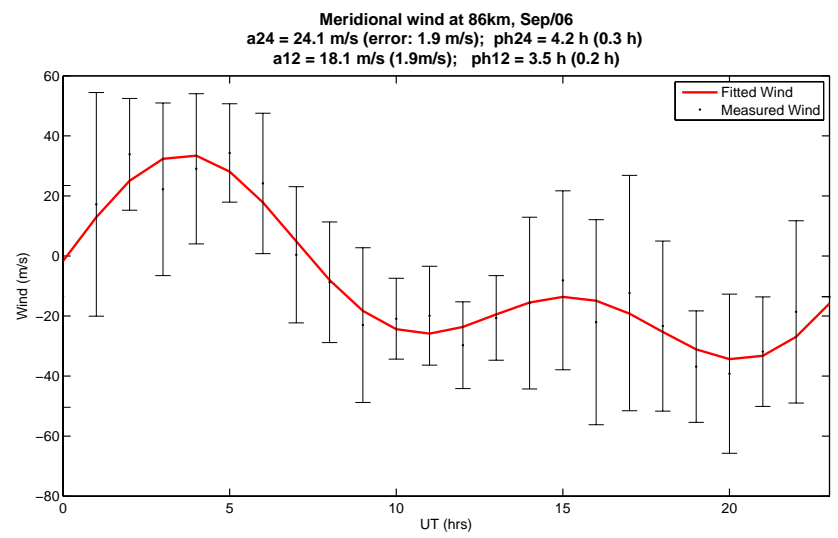

Fig. 1. Hourly averaged JASMET measurements (black dots) and tidal fits (red curve) from 0 to $23 \mathrm{~h}$ in UT for the meridional winds at $86 \mathrm{~km}$ in September 2006. The errors from the fit procedures are included in parenthesis. The vertical bars indicate the standard deviation of the hourly wind data.

glow layers and their Doppler shift (Killeen et al., 2006). The satellite precesses slowly and can cover $24 \mathrm{~h}$ in local time for every 60 days (Wu et al., 2008). With the assumption that there is no fast temporal variation, we perform the same harmonic fit (Eq. 1) to the 60-day averaged monthly TIDI data at $15^{\circ} \mathrm{S}$ from 2006 to 2007 (courtesy of Qian Wu of High Altitude Observatory) to extract tidal information so that the comparison with JASMET data can be made (see Table 2 for the monthly TIDI data used in comparison). Reconstructed daily TIDI diurnal and semidiurnal tides for zonal and meridional wind from the migrating $w 1$ (from SABER temperatures) and 7 nonmigrating (w4, w3, w2, s0, e1, e2, e3) components (Oberheide and Forbes, 2008) at $10^{\circ} \mathrm{S}, 77^{\circ} \mathrm{W}$ in 2007 are also compared with the corresponding JASMET data (see Table 2 for the daily TIDI data used in comparison). 

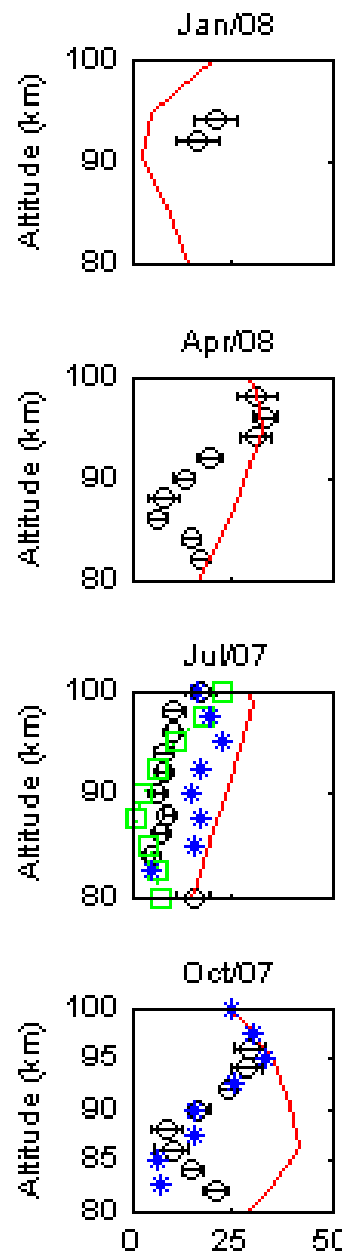

Amplitude (mis)
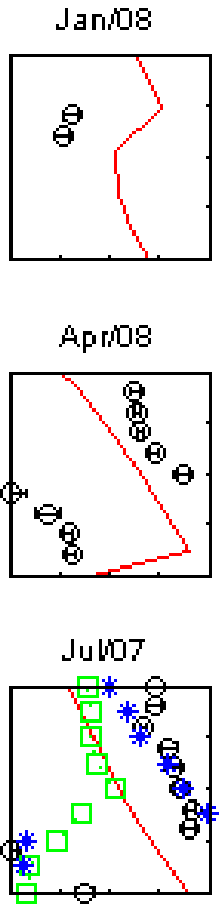

Detio7

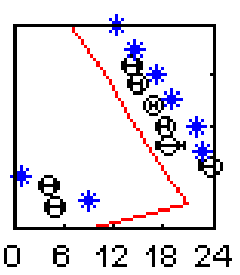

Phase (hrs)
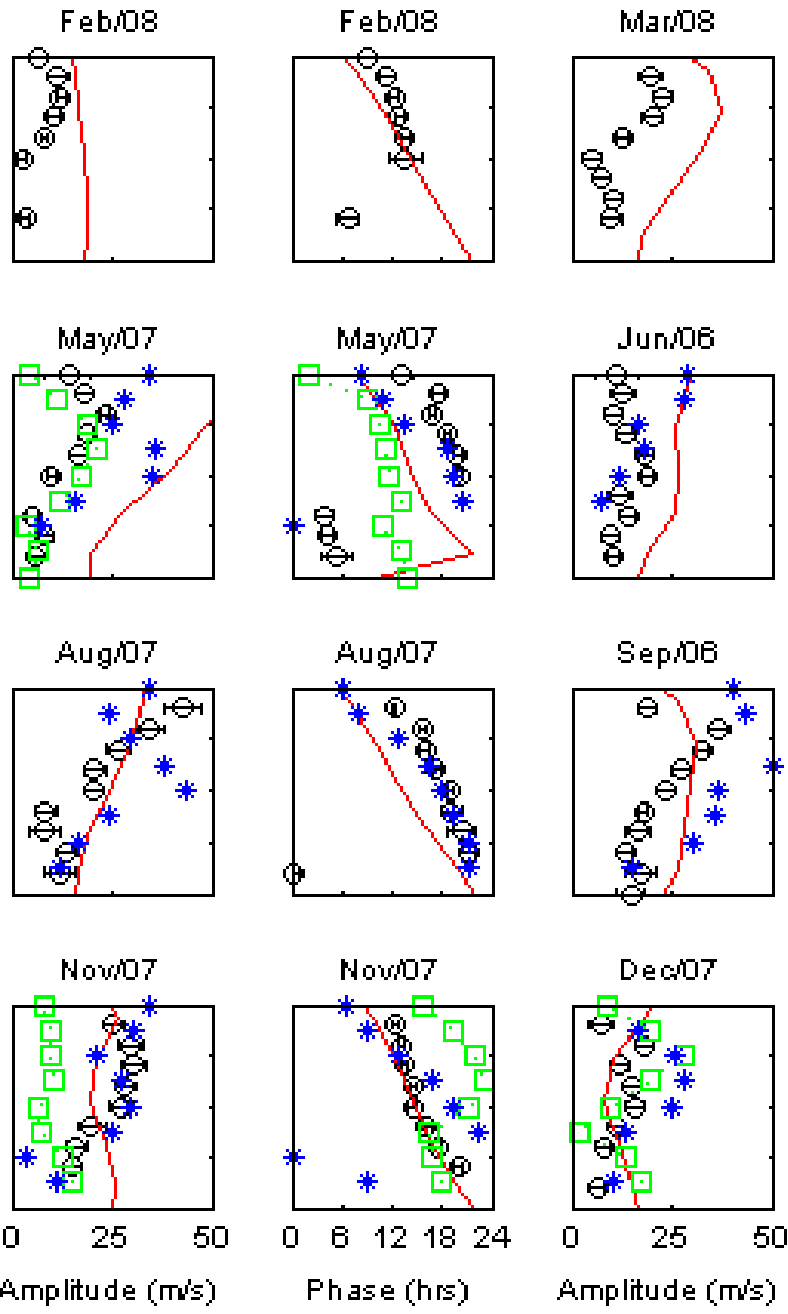
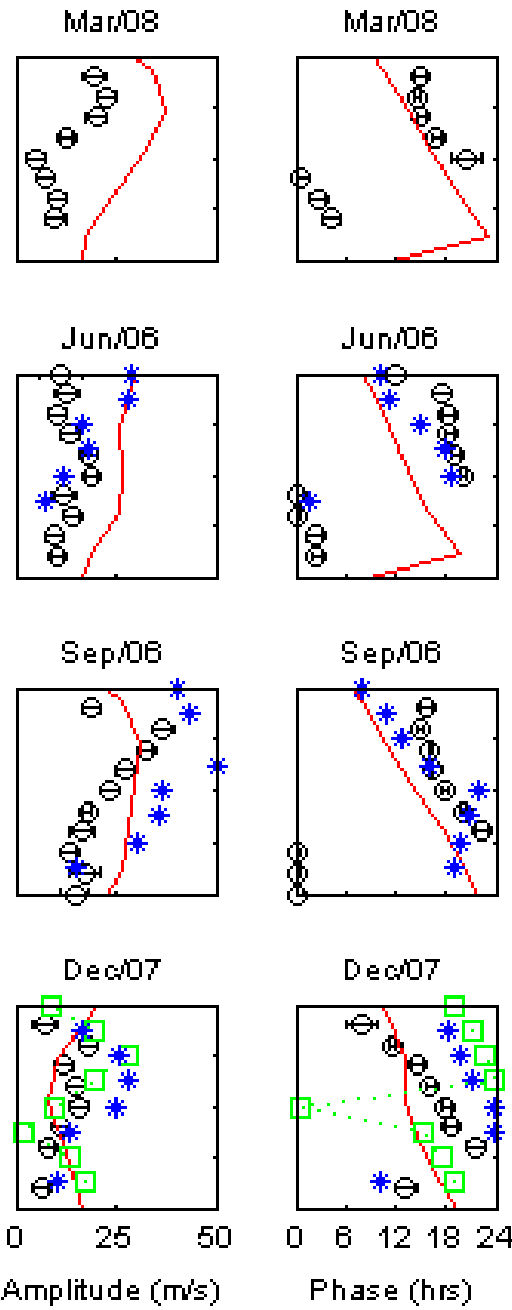

Fig. 2. Height profile of amplitude and phase (in UT) of zonal diurnal tides for 12 months. Red curves represent the GSWM02 model values taken from the website. Blue stars represent monthly TIDI values (Wu et al., 2008). Green squares represent daily TIDI values reconstructed from different modes (Oberheide and Forbes, 2008). Black circles with error bars represent JASMET observations.

The following section describes the vertical profiles of amplitude and phase. Thus the characteristics of tidal oscillations and their seasonal variations can be discussed.

\section{Results and discussion}

Diurnal and semidiurnal tidal analyses from 3-20 day JASMET zonal and meridional observations are compared with GSWM02 values and TIDI results. Since GSWM02 results are monthly model predictions and the two TIDI data sets reconstructed using different methods are 60-day averaged, reasonable disagreement with JASMET values would be expected. JASMET data should have more short-term variability than GSWM02 and TIDI.

\subsection{Diurnal tide}

Figures 2 and 3 present the altitude profiles of amplitude and phase of zonal and meridional diurnal tide for the available twelve months measured with JASMET in a 6 (3 months of amplitude and phase) $\times 4$ block. Profiles of GSWM02 model values and TIDI values reconstructed by different methods are also shown for available months. The phases in all the figures are defined as the UT in hours after midnight at which the maximum wind velocity occurs. Horizontal bars on the JASMET data points indicated the standard errors in the harmonic fit procedure. Uncertainties at the upper-most height of each profile tend to be larger because fewer meteors are detected in this region. GSWM02 and TIDI results both show stronger diurnal amplitudes of zonal and meridional wind in the equinox month and weaker amplitudes in solstice months. For most months, the model predictions are larger than those from TIDI analysis. 

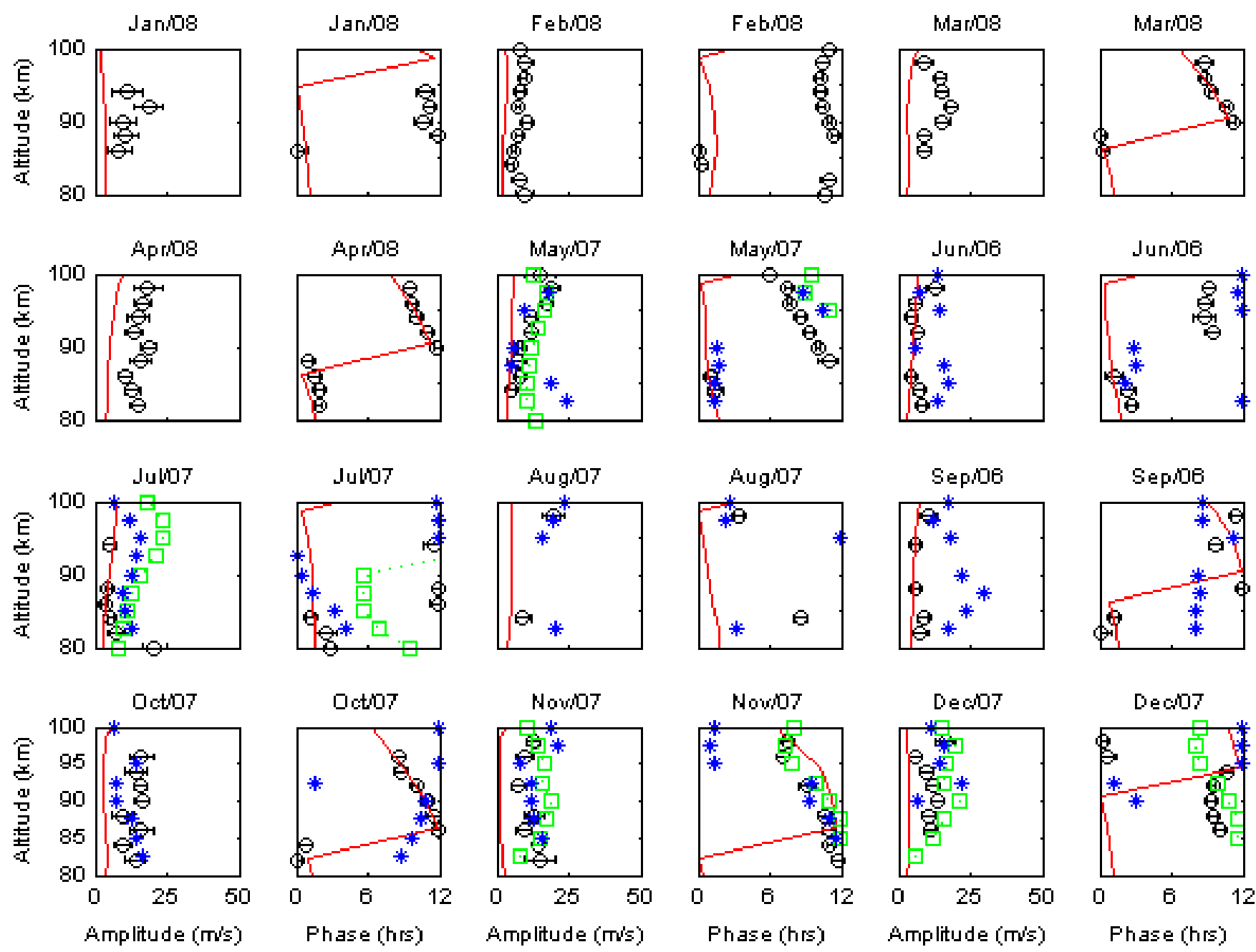

Fig. 3. Same as Fig. 2, but for meridional diurnal tides.

Amplitudes of the zonal diurnal wind from JASMET (Fig. 2) lie in the range $5-45 \mathrm{~m} / \mathrm{s}$ at all heights. Relatively high amplitude values of $30-45 \mathrm{~m} / \mathrm{s}$ are also observed during fall equinox months, i.e. August, September, October and November. Such seasonal behavior is consistent with both GSWM02 and TIDI. For most months, the zonal diurnal amplitudes decrease with altitude to around $84-90 \mathrm{~km}$, increase with altitude and reach maxima around $90-96 \mathrm{~km}$. The meteor radar at Borinquen, Puerto Rico also observed such increase till around $90 \mathrm{~km}$ then decrease with altitude (Bernard et al., 1981). JASMET observations agree with Jicamarca MST radar observations below $86 \mathrm{~km}$ (Countryman and Dolas, 1982), where the amplitudes are $<20 \mathrm{~m} / \mathrm{s}$. The growths with altitude in equinox months, i.e. March-April, August-October are much stronger than in other months. In July, the amplitudes remain almost constant with height. The slow growth rates were also observed in June and July over Trivandrum (Deepa et al., 2006) and April to June over Christmas Island (Chang and Avery, 1997). The magnitudes of zonal diurnal amplitude from two TIDI analyses are closer to JASMET observation than GSWM02, but they do not always follow the same altitude trends. The model zonal diurnal tide amplitudes have different trends with respect to altitude and tend to be larger than the observed values from February to July. In October, the model predictions show large differences to the agreeing JASMET and TIDI profiles lower than $95 \mathrm{~km}$.

The height profiles of zonal diurnal phases depicted in Fig. 2 show characteristics of an upward propagating wave with phase transitions in some months. The zonal diurnal phases from GSWM02 appear earlier than those of JASMET by $\sim 5-8 \mathrm{~h}$ except for in November where good agreement can be seen. Countryman and Dolas (1982) also showed earlier phases from theory than MST radar results at the same location. Comparisons between the JASMET observation and the monthly TIDI profiles (blue stars) show good agreement on phases in most months. 

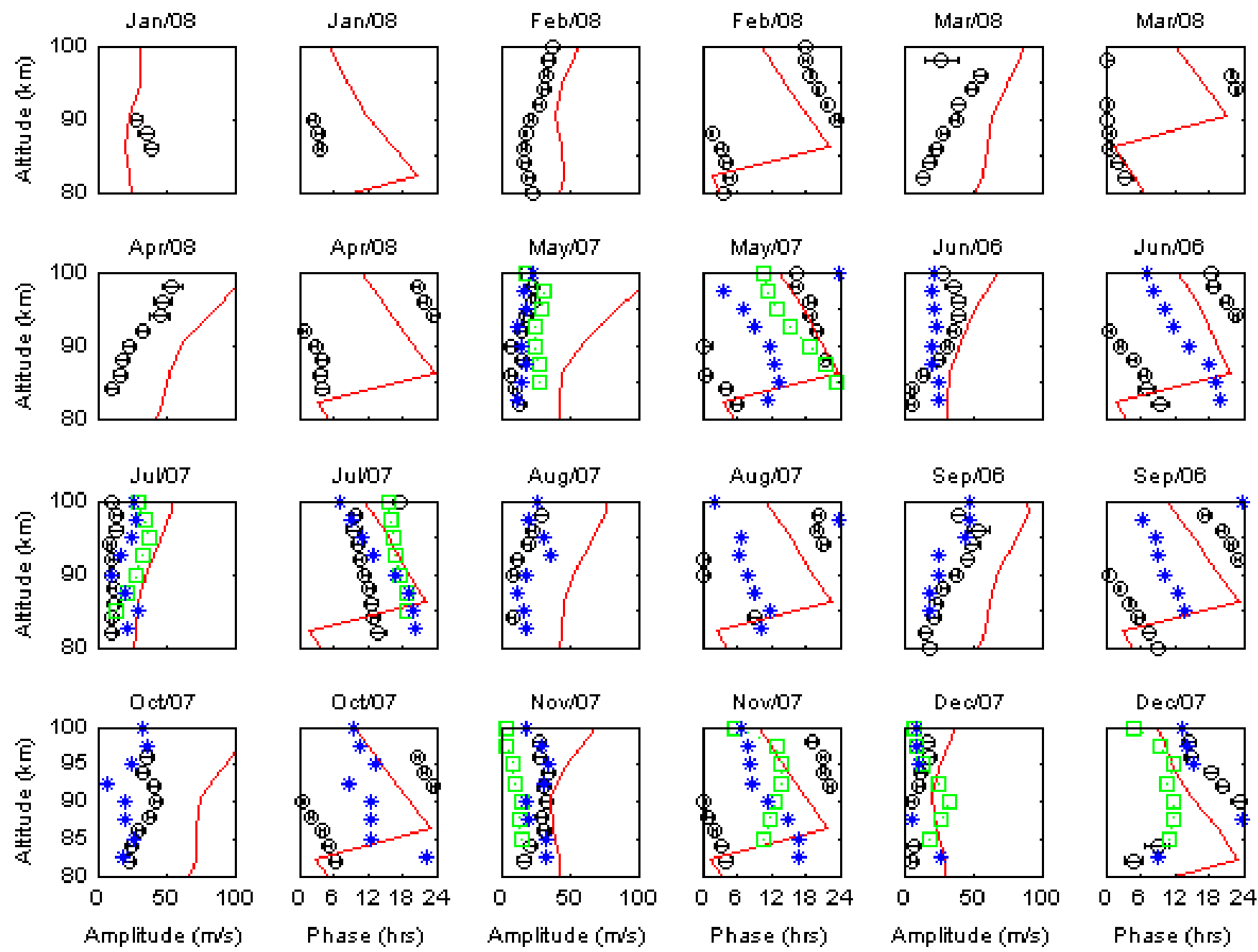

Fig. 4. Same as Fig. 2, but for zonal semidiurnal tides.

Figure 3 shows profiles of diurnal amplitude and phase for meridional component. The amplitude profiles in Fig. 3 are drawn in a larger scale $(0-100 \mathrm{~m} / \mathrm{s})$ than in Fig. $2(0-50 \mathrm{~m} / \mathrm{s})$ in order to accommodate the much larger GSWM02 prediction of the meridional component.

The JASMET and TIDI amplitudes of the meridional diurnal tide are generally ranging from $5-55 \mathrm{~m} / \mathrm{s}$ over JRO, greater than the zonal diurnal amplitudes. Studies from other equatorial locations also show greater meridional diurnal tide (Chang and Avery, 1997; Deepa et al., 2006). Relatively low amplitude values are observed in July and December. For most months, the amplitude increase consistently with altitude just like the model predicted. For July and December, the amplitude growth is weakest just like zonal diurnal. Less than $23 \mathrm{~m} / \mathrm{s}$ meridional diurnal amplitudes observed by Jicamarca MST radar (Countryman and Dolas, 1982) were in good agreement with those of JASMET below $86 \mathrm{~km}$ for most months.
While the magnitude of the meridional diurnal amplitude from JASMET observation agrees much better with both TIDI data sets than with the model, the phases between TIDI and JASMET data often differs by $6-12 \mathrm{~h}$ except for in July/August and December. Similar to the zonal diurnal phases, the GSWM02 phases also appear to occur earlier than those of JASMET in meridional components and the phase transitions are at lower altitudes for most months.

For both the zonal and meridional diurnal tide, the vertical wavelengths from JASMET agree well with GSWM02 results for most months. The zonal diurnal tide vertical wavelengths from JASMET and TIDI are shorter than that of GSWM in December and the meridional diunal tide vertical wavelength from JASMET and one profile of the TIDI data are longer than that of GSWM in July. These may indicate some of the modes that are not considered in the model but analysed in TIDI data have impact in Jicamarca. 

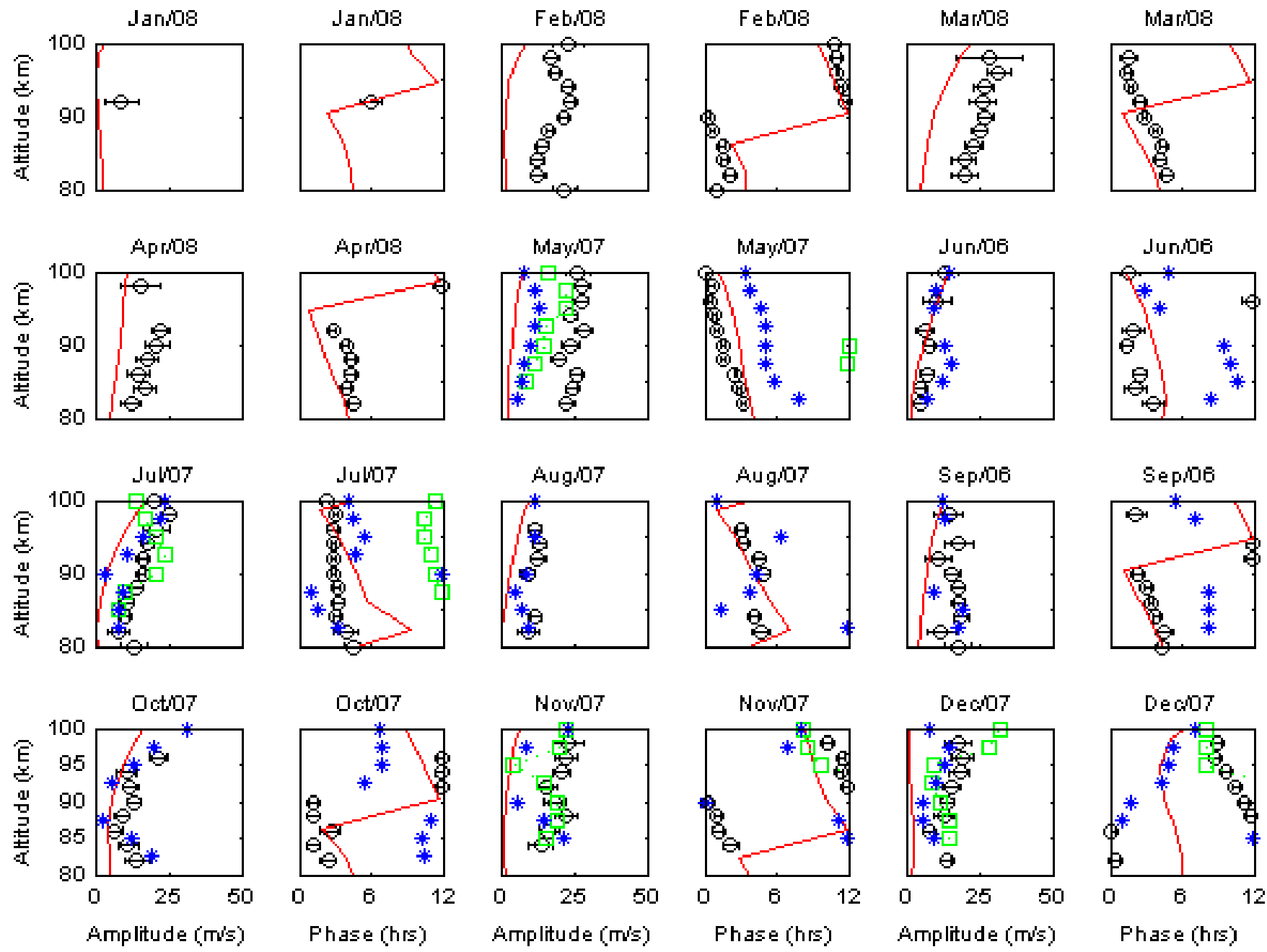

Fig. 5. Same as Fig. 2, but for meridional semidiurnal tides.

\subsection{Semidiurnal tide}

Figures 4 and 5 display the JASMET semidiurnal amplitude and phase profiles for zonal and meridional components from different months along with GSWM02 and TIDI profiles for comparison. Data from different sources all indicate that the amplitudes of the semidiurnal tide are weaker than the diurnal tide at JRO for both zonal and meridional components. Contrary to the overestimation of the diurnal tide amplitudes by GSWM02, the model underestimates semidiurnal amplitude for both zonal and meridional components every month over JRO. Deepa et al. (2006) also show underestimation of the model for semidiurnal tide. Comparison between the JASMET observation and the two TIDI profiles again shows better agreement on the magnitude of amplitudes.

Semidiurnal amplitudes for zonal component (Fig. 4) are mostly $<20 \mathrm{~m} / \mathrm{s}$ over JRO. The maxima usually occur at altitude between $90-98 \mathrm{~km}$. The growth rate with altitude is not as strong as for diurnal tide consistent with model prediction.
Phase profiles show upward propagating waves from JASMET. Similar to the comparison of diurnal phase profiles, zonal semidiurnal phase profiles from JASMET show phase transitions occur higher than GSWM02 prediction in most months. Except for some months with too few JASMET data to derive vertical wavelengths, in general, they agree well with the model results.

Figure 5 displays the profiles of amplitude and phase for meridional semidiurnal tides. The amplitudes of the meridional semidiurnal tide generally range from $5-25 \mathrm{~m} / \mathrm{s}$, greater than the zonal semidiurnal amplitude, but much weaker than the meridional diurnal amplitudes. For most months, the amplitude increase with altitude or reach maxima around 90 $95 \mathrm{~km}$. Values from GSWM02 show smaller magnitudes in semidiurnal amplitude for the meridional components except in June. Meridional semidiurnal amplitudes from both TIDI analyses show better agreement with JASMET values.

Lower altitude from GSWM02 where phase transition occurs can be observed in Feburary, October to December. For 


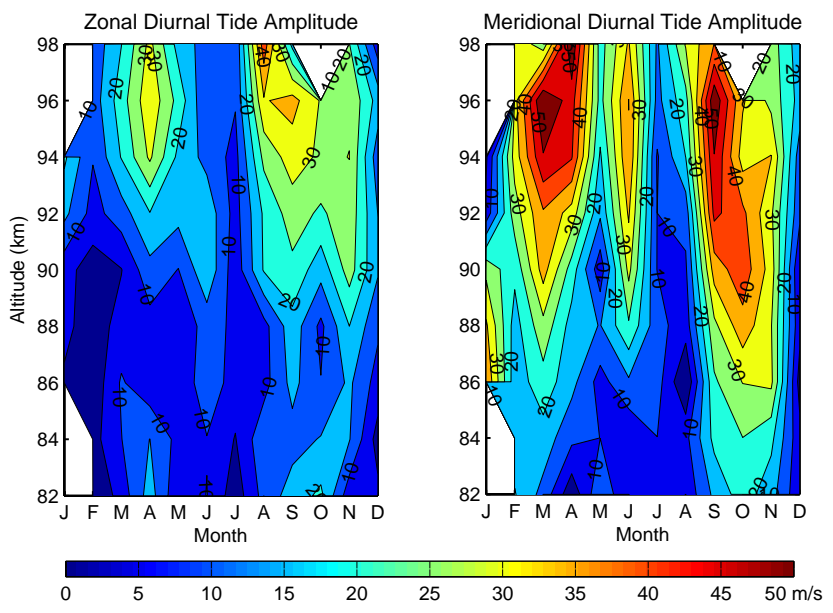

Fig. 6a. Twelve month contour plots of diurnal amplitude for zonal (left) and meridional (right) components.

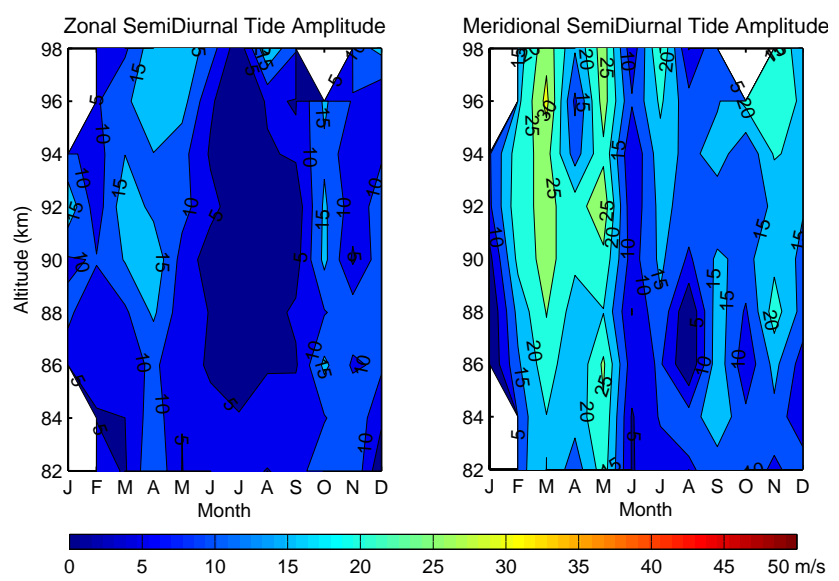

Fig. 6b. Same as Fig. 6a, but for semidiurnal amplitude.

the months with enough JASMET values, the vertical wavelengths are about the same as GSWM02 vertical wavelengths except in July.

\subsection{Seasonal variation}

Figure 6 contains height-time countour plots of the 12-month amplitudes for zonal and meridional components from 82$98 \mathrm{~km}$. The seasonal variation of tidal activity can be better appreciated in these graphs.

Diurnal amplitude (Fig. 6a) undergoes similar seasonal behavior and altitude variation in both components. There are two strong maxima in March/April and August/September. Other low latitude observations also showed that diurnal tides maximize in the equinoxes (Deepa et al., 2006). A second maximum can be observed in June, but only for meridional component. For the zonal component, the August/September maximum is stronger than the March/April maximum. The maxima for both components are observed around $94-98 \mathrm{~km}$.
Since these data are not from the same year, care must be taken in discovering semiannual variability in these figures. More measurements are needed for semiannual, annual, and interannual studies over JRO.

For the semidiurnal tide (Fig. 6b), seasonal and altitude variations are not as strong as for the diurnal tide. Largest amplitudes are observed in March-May. Minima are in June/July for both components. The weak seasonal variability in zonal semidiurnal component at equatorial region was also observed with HRDI and WINDII data (Burrage et al., 1995; McLandress et al., 1996).

\section{Summary}

In this paper, comparisons of tidal parameters measured in the equatorial MLT region by meteor radar JASMET $\left(11.95^{\circ} \mathrm{S}, 76.87^{\circ} \mathrm{W}\right)$ from twelve months in 2006-2008 with available TIDI satellite instrument and monthly GSWM02 model results are presented.

The diurnal tide is prominent during the observations. The amplitude of the meridional diurnal tide reaches maximum around $55 \mathrm{~m} / \mathrm{s}$, stronger than that of the zonal diurnal tide, which is around $45 \mathrm{~m} / \mathrm{s}$. The semidiurnal tides are weaker with maxima $\sim 20 \mathrm{~m} / \mathrm{s}$ and $30 \mathrm{~m} / \mathrm{s}$ for zonal and meridional components respectively. The zonal diurnal amplitudes often reach maxima around $90-96 \mathrm{~km}$ then decrease with altitude. The meridional diurnal amplitude mostly increase with height. The phase profiles of both components indicate upward propagation of the waves.

The observed diurnal amplitudes are less than the GSWM02 values for both zonal and meridional components in most months, but the observed semidiurnal amplitudes are larger than the model values. The comparison with two TIDI analyses show better agreement on the magnitude of both diurnal and semidiurnal amplitudes.

Seasonal variation is also observed in JASMET tidal components. The diurnal tides are strong during two equinoxes for both zonal and meridional components consistent with model and TIDI results. Semidiurnal meridional amplitudes are strong during March-May while semidiurnal zonal amplitudes have weak seasonal variation. A larger data set would allow further studies on seasonal and interannual variabilities in the equatorial MLT region.

Acknowledgements. This project has been funded by the National Science Foundation under Grants ATM-0422837. JRO is a facility of the Instituto Geofísico del Perú and is operated with support from the NSF Cooperative Agreement ATM-0432565 through Cornell University. The JASMET radar hardware specifications and data processing software were provided by Atrad Pty. Ltd., Adelaide, Australia. The hardware is provided by JRO. We warmly acknowledge the radar system support and operation by Luis Condori, Jorge Chau and all JRO engineers. We wish to thank Qian Wu and Jens Oberheide for supplying TIDI data. The authors are also grateful to M. Hagan for the GSWM02 values taken from the website. 
Topical Editor K. Kauristie thanks K. Kishore Kumar and another anonymous referee for their help in evaluating this paper.

\section{References}

Avery, S. K., Vincent, R. A., Phillips, A., Manson, A. H., and Fraser, G. J.: High-latitude tidal behavior in the mesosphere and lower thermosphere, J. Atmos. Terr. Phys., 51(7-8), 595-608, 1989.

Badadzhanov, P. B., Kal'chenko, B. V., Kashcheyev, B. L., and Fedynskiy, V. V.: Motion of air masses in the lower thermosphere near the equator, Geophysics, 208, 39-42, 1973

Bernard, R., Fellous, J. L., Massebeuf, M., and Glass, M.: Simultaneous meteor radar observations at Monpazier (France, $44^{\circ} \mathrm{N}$ ) and Punta Borinquen (Puerto-Rico, $18^{\circ} \mathrm{N}$ ). I - Latitudinal variations of atmospheric tides, J. Atmos. Terr. Phys., 43(5-6), 525$533,1981$.

Burrage, M. D., Wu, D. L., Skinner, W. R., Ortland, D. A., and Hays, P. B.: Latitude and seasonal dependence of the semidiurnal tide observed by the high-resolution Doppler imager, J. Geophys. Res., 100(D6), 11313-11321, 1995.

Cervera, M. A. and Reid, I. M.: Comparison of simultaneous wind measurements using colocated VHF meteor radar and MF spaced antenna radar systems, Radio Sci., 30(4), 1245-1261, 1995.

Chang, J. L. and Avery, S. K.: Observations of the diurnal tide in the mesosphere and lower thermosphere over Christmas Island, J. Geophys. Res., 102(D2), 1895-1907, 1997.

Countryman, I. D. and Dolas, P. M.: Observations on Tides in the Equatorial Mesosphere, J. Geophys. Res., 87(C2), 1336-1342, 1982.

Deepa, V., Ramkumar, G., Antonita, M., Kumar, K. K., and Sasi, M. N.: Vertical propagation characteristics and seasonal variability of tidal wind oscillations in the MLT region over Trivandrum $\left(8.5^{\circ} \mathrm{N}, 77^{\circ} \mathrm{E}\right)$ : first results from SKiYMET Meteor Radar, Ann. Geophys., 24, 2877-2889, 2006, http://www.ann-geophys.net/24/2877/2006/.

Forbes, J. M., Zhang, X., Talaat, E. R., and Ward, W.: Nonmigrating diurnal tides in the thermosphere, J. Geophys. Res., 108(A1), 1033, doi:10.1029/2002JA009262, 2003.

Groves, G. V. and Forbes, J. M.: Mean zonal and meridional accelerations and mean heating induced by solar tides for equinox and solstice conditions, Planet. Space Sci., 33(3), 283-293, 1985.

Hagan, M. E. and Forbes, J. M.: Migrating and nonmigrating diurnal tides in the middle and upper atmosphere excited by tropospheric latent heat release, J. Geophys. Res., 107(D24), 4754, doi:10.1029/2001JD001236, 2002.

Hagan, M. E. and Forbes, J. M.: Migrating and nonmigrating semidiurnal tides in the upper atmosphere excited by tropospheric latent heat release, J. Geophys. Res., 108(A2), 1062, doi:10.1029/2002JA009466, 2003.

Holdsworth, D. A., Reid, I. M., and Cervera, M. A.: Buckland Park all-sky interferometric meteor radar, Radio Sci., 39, RS5009, doi:10.1029/2003RS003014, 2004.

Jones, J., Webster, A. R., and Hocking, W. K.: An improved interferometer design for use with meteor radars, Radio Sci., 33(1), 55-65, 1998.
Killeen, T. L., Wu, Q., Solomon, S. C., Ortland, D. A., Skinner, W. R., Niciejewski, R. J., and Gell, D. A.: TIMED Doppler Interferometer: Overview and recent results, J. Geophys. Res., 111, A10S01, doi:10.1029/2005JA011484, 2006.

Manson, A. H., Meek, C. E., Teitelbaum, H., Vial, F., Schminder, R., Kürschner, D., Smith, M. J., Fraser, G. J., and Clark, R. R.: Climatologies of semi-diurnal and diurnal tides in the middle atmosphere $(70-110 \mathrm{~km})$ at middle latitudes $\left(40-55^{\circ}\right)$, J. Atmos. Terr. Phys., 51(7-8), 579-593, 1989.

Manson, A. H., Meek, C., Hagan, M., Koshyk, J., Franke, S., Fritts, D., Hall, C., Hocking, W., Igarashi, K., MacDougall, J., Riggin, D., and Vincent, R.: Seasonal variations of the semi-diurnal and diurnal tides in the MLT: multi-year MF radar observations from $2-70^{\circ} \mathrm{N}$, modelled tides (GSWM, CMAM), Ann. Geophys., 20, 661-677, 2002,

http://www.ann-geophys.net/20/661/2002/.

McLandress, C., Shepherd, G. G., and Solheim, B. H.: Satellite observations of thermospheric tides: Results from the Wind Imaging Interferometer on UARS, J. Geophys. Res., 101, 4093-4114, 1996.

Oberheide, J. and Forbes, J. M.: Tidal propagation of deep tropical cloud signatures into the thermosphere from TIMED observations, Geophys. Res. Lett., 35, L04816, doi:10.1029/2007GL032397, 2008.

Pancheva, D., Mitchell, N. J., Hagan, M. E., Manson, A. H., Meek, C. E., Yi Luo, Jacobi, Ch., Kürschner, D., Clark, R. R., Hocking, W. K., MacDougall, J., Jones, G. O. L., Vincent, R. A., Reid, I. M., Singer, W., Igarashi, K., Fraser, G. I., Nakamura, T., Tsuda, T., Portnyagin, Yu., et al.: Global-scale tidal structure in the mesosphere and lower thermosphere during the PSMOS campaign of June-August 1999 and comparisons with the globalscale wave model, J. Atmos. Solar-Terr. Phys., 64(8-11), 10111035, 2002.

Portnyagin, Y. I., Solovjova, T. V., Makarov, N. A., Merzlyakov, E. G., Manson, A. H., Meek, C. E., Hocking, W., Mitchell, N., Pancheva, D., Hoffmann, P., Singer, W., Murayama, Y., Igarashi, K., Forbes, J. M., Palo, S., Hall, C., and Nozawa, S.: Monthly mean climatology of the prevailing winds and tides in the Arctic mesosphere/lower thermosphere, Ann. Geophys., 22, 33953410, 2004, http://www.ann-geophys.net/22/3395/2004/.

Scholefield, A. J. and Alleyne, H.: Low latitude meteor wind observations, J. Atmos. Terr. Phys., 37, 273-286, 1975.

Vincent, R. A., Tsuda, T., and Kato, S.: Asymmetries in mesospheric tidal structure, J. Atmos. Terr. Phys., 51(7-8), 609-616, 1989.

Vincent, R. A., Kovalam, S., Fritts, D. C., and Isler, J. R.: Longterm MF radar observations of solar tides in the low-latitude mesosphere: Interannual variability and comparisons with the GSWM, J. Geophys. Res., 103(D8), 8667-8683, 1998.

Wu, Q., Ortland, D. A., Killeen, T. L., Roble, R. G., Hagan, M. E., Liu, H., Solomon, S. C., Xu, J., Skinner, W. R., and Niciejewski, R. J.: Global distribution and interannual variations of mesospheric and lower thermospheric neutral wind diurnal tide: 1. Migrating tide, J. Geophys. Res., 113, A05308, doi:10.1029/2007JA012542, 2008. 